\title{
Exciting Developments for 2005
}

\author{
Freek J. Zijlstra
}

Department of Anesthesiology, Erasmus MC, Centre location, PO Box 2040, 3000 CA Rotterdam, The Netherlands; f.zijlstra@erasmusmc.nl

It is again a pleasure to welcome readers of the journal at the start of a new volume of the rapid journal Mediators of Inflammation. While in 2005 this journal will look much the same as it has been in the past, starting with this issue one main change has been made: the journal has changed publishers from Taylor \& Francis to Hindawi Publishing Corporation. This change of the publisher has not interfered with the publication of research papers currently under submission.

The Editors herewith would like to thank the staff at Taylor \& Francis for their help in the further development of this publication into an excellent journal in the field of immunology and inflammation.

Last year, we observed a growing interest in the field of immunopharmacology of inflammation, resulting in a continuous flow of research papers. Manuscripts were submitted from all over the world, from Brazil to Japan, from Scandinavia to South Africa. The impact factor of the journal currently fluctuates around 1.00, which shows a significant rise in impact since 2002 when the figure was 0.69 . Hopefully an increase in high-quality submissions will help improve the journal's impact even further in 2005 .

Authors are encouraged to submit their papers by electronic mail in order to improve the reviewing process as well as the speed of acceptance and publication. Following acceptance, the manuscript will be available on the website of the journal, http://mi.hindawi.com, as soon as possible. Both the Editors and Hindawi Publishing Corporation will do everything possible for a publication speed of approximately 4 months from submission to publication, which is extremely good for a bimonthly journal.

Meanwhile, the Editorial Board has been streamlined and the main Editorial positions consolidated.

We look forward to receiving innovative papers for Mediators of Inflammation on all aspects of the immunology, molecular biology, and pharmacology of inflammation. In particular, papers describing clinical research and how to manipulate through specific pharmacological intervention are strongly welcomed. We are proud to publish all these peer-reviewed manuscripts in glossy print, but papers will of course also be available in electronic form on the Internet.

As a final note, I would like to announce the introduction of a new feature beginning with Volume 2005 of Mediators of Inflammation, a hybrid open access option. What this option will do is allow authors to make their articles freely available online, without any subscription or registration barriers, by paying a one-time "Open Access Charge." I would encourage all of our authors to consider this new innovative feature. Now I would like to welcome you all to Volume 2005 of Mediators of Inflammation.

Freek J. Zijlstra 


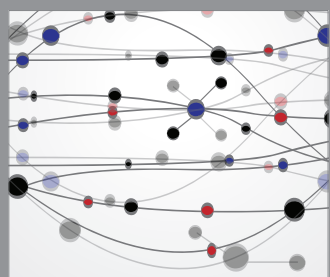

The Scientific World Journal
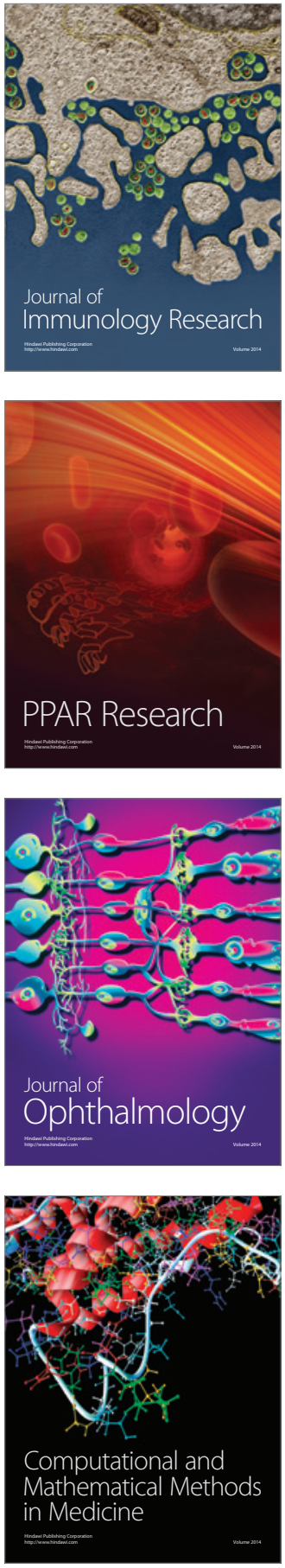

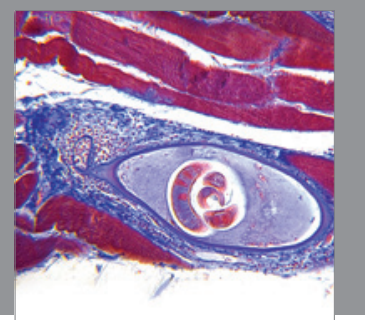

Gastroenterology

Research and Practice
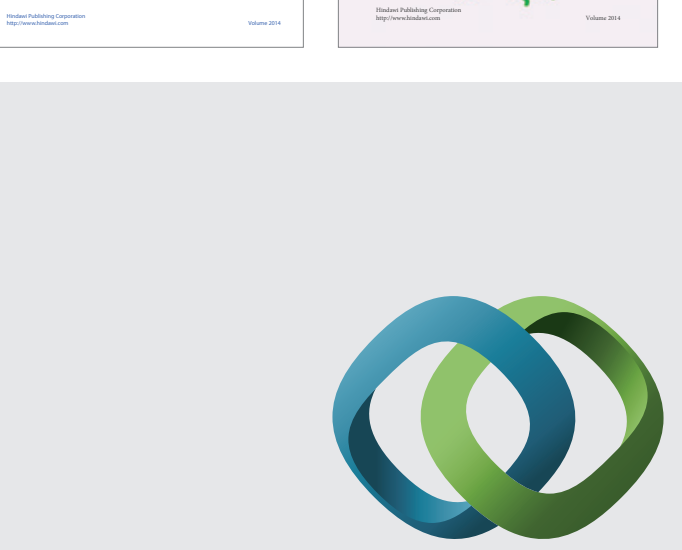

\section{Hindawi}

Submit your manuscripts at

http://www.hindawi.com
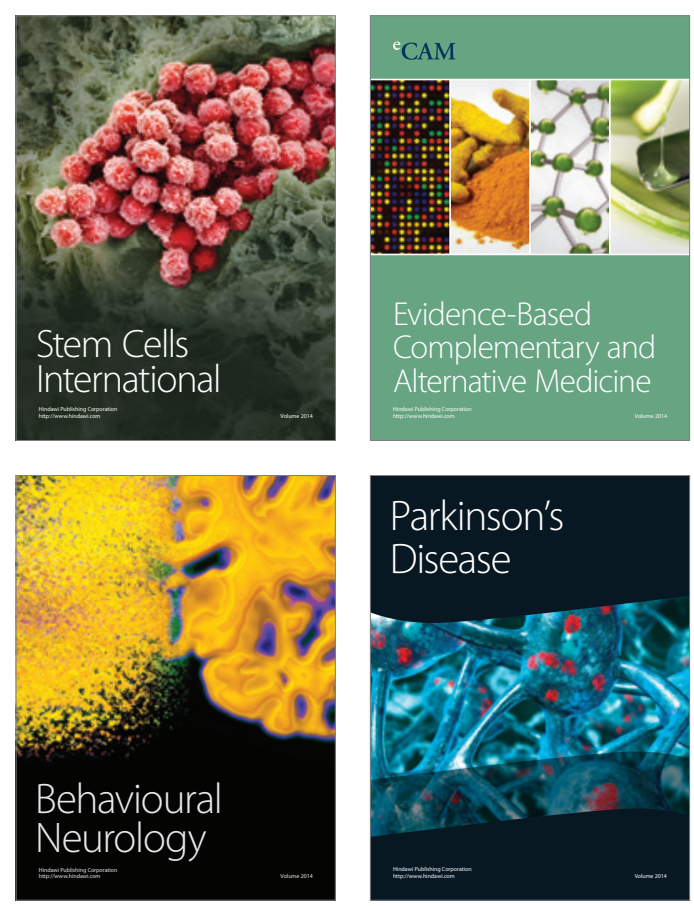

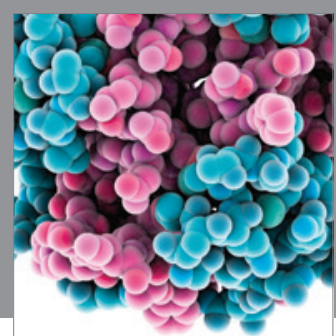

Journal of
Diabetes Research

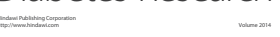

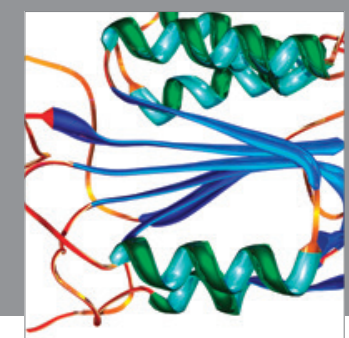

Disease Markers
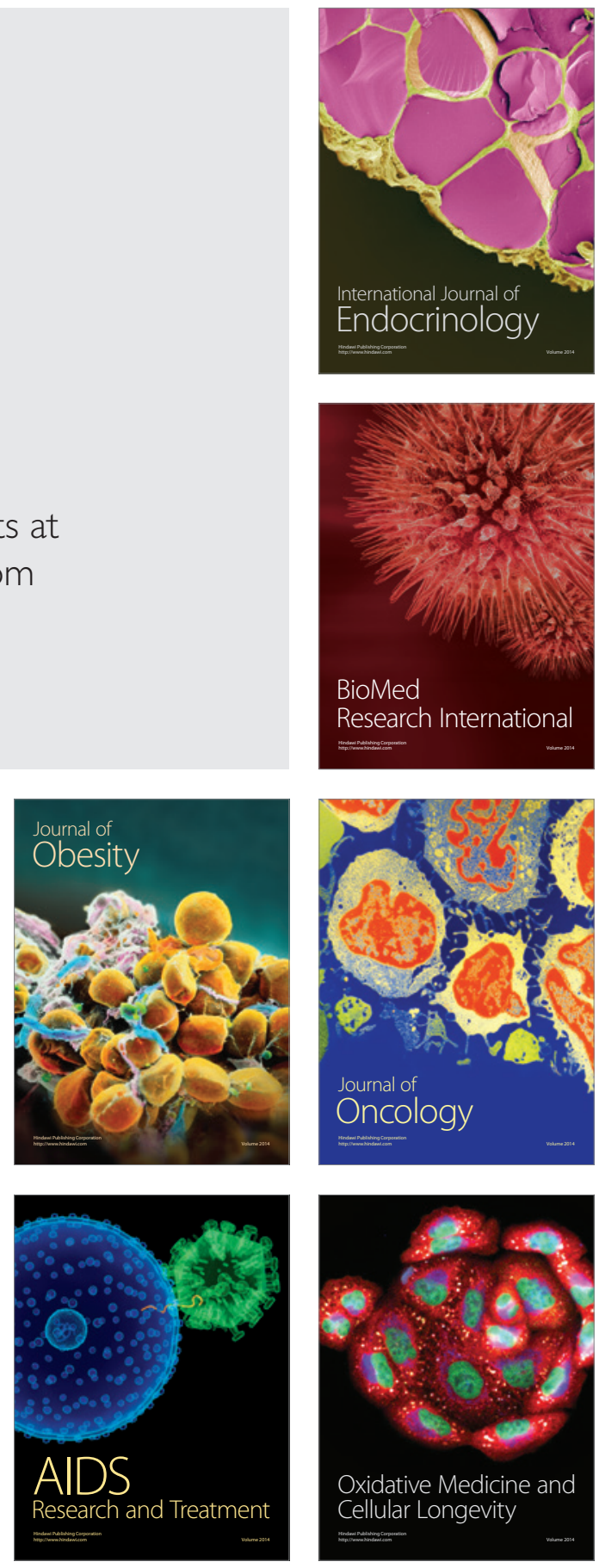